\title{
The formation of Coasean institutions to provide university knowledge for innovation: a case study and econometric evidence for Switzerland
}

\author{
Dominique Foray ${ }^{1} \cdot$ Martin Woerter ${ }^{2}$ (D)
}

Accepted: 25 September 2020 / Published online: 14 October 2020

(c) The Author(s) 2020

\begin{abstract}
"Coasean" institutions are an alternative institutional form that provides a solution to some market and coordination failures. As such they can weaken considerably the case for public subsidies in a vast range of context. They are "market-based" and an inexpensive way to address the public good issues of R\&D. They are, however, a largely overlooked institutional option. Early theoretical notions emphasize the advantages of such an institutional setting, however, broader empirical evidence about their effectiveness is lacking. We apply two different empirical approaches to assess the relationship between "Coasean" institutions and the innovation performance of SMEs. In a case study, we investigate Inspire AG, a successful bottom-up, institutional invention in the spirit of a "Coasean" institution. To assess the general validity of this model, we use representative firm-level data to econometrically investigate the relationship between "Coasean" institutions and the sales share of innovative products. "Coasean" institutions are positively related with innovative sales only if the company has a sufficiently large absorptive capacity for external knowledge. This positive moderating effect of "Coasean" institutions for the innovation performance is larger for SMEs. Our empirical findings provide a strong case for policies aimed at encouraging the operation of this type of institution.
\end{abstract}

Keywords R\&D collaboration · Coasean institutions · Case study · Firm-level panel data Innovation performance

JEL Classification $025 \cdot 031 \cdot 038$

Martin Woerter

woerter@kof.ethz.ch

Dominique Foray

dominique.foray@epfl.ch

1 College of Management, EPFL, ODY station 5, 1015 Lausanne, Switzerland

2 ETH Zürich, KOF Swiss Economic Institute, Leonhardstrasse 21, 8092 Zurich, Switzerland 


\section{Introduction}

In many ecosystems of innovation and entrepreneurship, one of the important gaps to be addressed by policies is the provision of inputs that most small and medium companies can draw on, even if they do not contribute to their production.

At a conceptual level, the centrality of such inputs to allow firms to develop innovative projects is a recurrent topic in the Hausmann and Rodrik literature devoted to industrial policy (Hausmann and Rodrik 2006; Rodrik 2007). Such inputs include specialized skills, research about the basic principles of the design and manufacturing of the goods produced by the considered SMEs, the design of more useful specialized equipment, as well as other specialized services for innovation. Some of these goods are private goods but many of them have the features of quasi-public goods.

At empirical level, Berger (2013) argues that-based on numerous case studies in the US, Germany and China - the lack of such resources can be a real problem in many ecosystems, resulting in firms that are home alone. Proactive public policies aimed at providing these goods are therefore needed. However, policies of this kind are proven to be complex and difficult because most of these goods are technology or sector specific. Policies aimed at providing sector-specific capabilities and infrastructures therefore require a lot of information-a problem which is obviously very difficult to solve in the case of a central public agency.

However, there is a mechanism that could avoid this informational burden. It involves the creation of private institutions by the economic agents themselves, in order to solve the collective action problems raised by the provision of specific quasi-public goods. This class of mechanism is also referred to as "Coasean Institutions"-named after Ronald Coase (1937, 1960), who developed the idea that the existence of externalities and opportunities for collective actions induce the creation of institutions by the private agents themselves (instead of relying on the classical Pigou and Samuelson solutions). In their article published in 1993, Weder and Grubel identify the importance of such mechanism in the innovation systems of two countries (Japan and Switzerland); which in no way implies that such mechanisms do not exist elsewhere.

As effective and efficient means for providing the required specific quasi-public goods, the advantages of these mechanisms are obvious: Firms are in a better position than the state to decide what kind of capabilities and coordination devices they need; and the opportunity cost of public funding is minimized since, very often, such institutions run without public money or very little. In this case, "good" managers, who understand how collective or coordination actions can solve a wide range of problems concerning public goods, minimize the magnitude of market failures and the subsequent need for public policy in the respective countries and sectors (Ghemawat 2017). The centrality of these institutions in some countries is also an interesting point to address as the literature predicts limitations caused by the existence of transaction costs and uncertainty (Weder and Grubel, ibid.)

In this paper, we further develop and continue the work by Weder and Grubel to highlight the centrality of such institutions in modern economies. Switzerland will be used for both the case study and the statistical analysis.

In the case study, we investigate Inspire AG, a public limited company located in the region of Zürich. This company is an example of how the formation of a Coasean institution represents an efficient response by small companies in the sectors of machine-tools, micro-technology, optoelectronics and mechanical engineering, which are currently facing critical challenges in the area of digitalization and additive manufacturing. Due to the great 
difficulties companies in these sectors generally experience in building R\&D partnerships with the regions top university, Inspire initiated the development of an interface-a platform that incorporates several research groups who maintain strong ties to university professors and who are the main contact point for companies in their search for research partnerships, technical services as well as specialized training programs. Small firms can coordinate among themselves to enable collaboration with the university. The case will be extensively documented and discussed.

Against this background, we present comprehensive econometric analyses in order to observe and measure the importance of Coasean institutions in the Swiss innovation ecosystem. For the main estimations we use survey data about knowledge and technology transfer activities between universities and companies. The survey has been carried out in 2018 by the ETH Zürich, KOF Swiss Economic Institute. It was commissioned by the Swiss State Secretary for Education, Research, and Innovation (SERI) and provides the official data on transfer activities of enterprises. The data set comprises firm-level information for 1343 companies. We also conducted a number of robustness tests using alternative data sets in particular to control for unobserved heterogeneity.

The survey includes a question about the public transfer partners. It presents a list of institutions that does not only include universities and universities of applied sciences, but also technology competence centers that fulfil the criteria of a Coasean institution. Inspire AG is explicitly listed as an example. We use this question to measure Coasean institutions in our empirical setting.

The econometric results reveal that Coasean institutions significantly improve the commercial success of new and essentially modified products if the company has a sufficiently high absorptive capacity. We measure the absorptive capacity by means of R\&D expenditures. We observe the positive relationship in particular for SMEs with considerable investments in R\&D. Here the marginal contribution of Coasean institutions to the R\&D expenditure of an SME is significantly stronger; we observe a marginal effect of 3 compared to 0.5 if an SME does not engage in Coasean institutions. The available cross-sectional data does not allow us to claim causality of the effects.

This has policy implications, which will be discussed towards the end of the paper. These implications are subtle since, by definition, the very ability of firms to create Coasean institutions should lead to a weakening of any rationale for policies aimed at providing public goods (for instance through direct R\&D subsidies). However, the significant effect that Coasean arrangements have on the innovative performance of firms makes a strong case for strengthening such ability through various types of interventions, which can be derived from the theory of Coasean institutions.

The paper is organized as follows: First, we present some theoretical notions about the economics of Coasean institutions. Second, we introduce the empirical methods we applied in order to assess the importance of such institutions for the innovation performance of firms. It consists of a comprehensive case study and a broad econometric verification of the general validity of the findings of the case study. Third, we present the econometric findings. In conclusion (fourth section), we will discuss our findings as well as ways to encourage and support the formation of Coasean institutions to enhance innovation capacities and capabilities of SMEs in various industries. 


\section{Theoretical notions}

In this section, we present some theoretical elements of Coasean institutions created by firms to address the issue of university-industry knowledge and technology transfers.

\subsection{The economics of Coasean institutions and the R\&D and innovation problems}

Our working hypothesis is that an important source of market failure that arises in the context of innovation is that there are certain inputs that companies need for their innovation projects. The problem is that small companies cannot afford to produce these goods on their own and moreover some of these goods are quasi-public goods and raise therefore a typical problem of positive externalities. Public funding is therefore required in order to provide these goods that small companies need to achieve their innovation objectives.

However, the extent to which such a public funding solution can be applied is rather limited by the fact that these goods are mostly "industry-specific". We are referring to resources that are in many cases both quasi-public (in the economist's sense) and industry specific. Typical examples of industry specific quasi-public goods are a particular set of specialized skills, some applied research fields of industry-wide relevance, a set of industry-specific technological services, or a program to support the provision of information about the advantages of a generic product.

When the required quasi-public goods are sector or technology specific, the informational requirements at a practical level raise serious questions about the feasibility of government policy to address such problems in the real world (Aghion et al. 2009). The risk is to pile up a great number of institutions which poorly address the specific capabilities needed by firms.

Because of these informational problems, a different solution can be considered, according to the principles developed by Coase $(1937,1960)$. A typical Coasean response to this problem is that such market failures can induce the creation of private institutions capable of providing the needed quasi-public goods: Why can't firms in the same industry join forces and form a club to internalize most of the external benefits and fund collectively the provision of the industry-specific public goods?

If private agents are capable to undertake the needed collective action (forming a club), then the case for public subsidies is weakened significantly: there are fewer public goods than is commonly supposed. In the case of industry specific public goods, the Coasean solution has an additional "informational" advantage relative to the public finance solution: firms are in a better position than the State to perceive opportunities and risks in terms of the specific public inputs they need.

The former literature has extensively discussed the feasibility and boundary conditions of Coasean solutions to R\&D problems at a theoretical level, while exploring empirically many real cases. A few studies have also addressed the issue of the organizational design of a club devoted to the provision of specific public goods. Most of the literature focus on the voluntary formation of research organizations devoted to internalizing R\&D spillovers; typically, a R\&D consortium. Only a small fraction looks at organizations which aim at providing the whole range of specific public goods (not only research but also training, services, technology supply); typically, an industry association. We assume that these two cases are rather different as regarding the main problems to be solved in terms of transaction costs, intellectual property rights, and organizational design. 
Our case study and econometric analysis are related to the second case: the formation of clubs by small firms in order to secure the provision of specific public goods-such as applied research or specialized skills. In this case, a club is formed with the goal to become a credible and interesting partner for top institutions (e.g. a university) that can provide the needed specific public inputs; something that a single SME cannot easily pretend to be. Our analysis is therefore not centrally focusing on the economics of R\&D consortium and this is why we don't provide an extensive literature review on this topic. While not proposing it, it is useful to briefly mention the main issues which are addressed by the literature on Coasean institutions in the area of R\&D and innovation.

A first strand of literature deals with the normative comparison of the suitability of a Coasean solution to public subsidies. Swann (2003) for instance explores under what conditions the club solution is likely to be an efficient arrangement relative to public finance. The main problem identified by Swann deals with the identification ex ante of the type of diffusion of knowledge likely to occur and the firms that will benefit. This problem is related to the fact that forming a Coasean institution involves transaction costs and, if the club of beneficiaries is large and dispersed, these can be substantial. By contrast, the public finance solution involves relatively low transaction costs. Given that problem, the most profitable club may not be the largest. While limited size will not achieve perfect internalization, it will keep transaction costs at an acceptable level.

A second strand of literature addresses the issue of appropriability and intellectual property. For a firm considering its entry into a voluntary formation of an R\&D club, the tradeoff is between benefiting from other's R\&D while not giving away too much of its own knowledge. Building on the economic theory of clubs, Antonelli and Foray (1992) provide a formal analysis of the representative firm which has to manage such a tension between the retention and the disclosure of new technological knowledge. There is considerable evidence that intellectual property issues are the most contested area in negotiating R\&D cooperation agreements (Cassiman and Veugelers 2002; Branstetter and Sakakibara 2002) and can give rise to ingenious mechanisms to provide solutions to the trade-off (Cassier and Foray 2002). In this respect, the literature on collective invention and the economic analysis of Coasean models in the domain of innovation overlap to a certain extent. "Collective invention" is a terminology to address explicitly the issue of intellectual property in instances and contexts of knowledge sharing among competing organizations. Collective invention is for instance defined as "technological advances driven by knowledge sharing among a community of inventors who are often employed by organizations with competing intellectual property interests" (Powell and Giannella 2010). This concept therefore encompasses voluntary associations which in many cases involve a Coasean logic.

A third strand of literature involves the question of the design of Coasean institutions which could address some of the fundamental problems raised by the operation of voluntary R\&D collaboration. One of these fundamental problems involves the risk of monopolization. By definition, the club does not manage the resources it provides itself in the same way as the traditional model of publicly funded resources. Why should clubs allow benefits to spill-over to non-members, particularly if these non-members are actual or potential rivals? Moreover, new entries into the considered industry will be problematic; either the new firms will be disadvantaged because they are not members or they will free ride on existing research, depending on the exact nature of the intellectual property regime and its effectiveness. And existing members of the consortium may be able to direct research towards avenues that endure barriers to entry for new firms. The other fundamental problem deals with the risks of disagreements that can arise between members about the directions of research or the nature of the 
capabilities that the club should fund. How can this kind of disagreement be solved if firms have different perceptions of what is needed for themselves and for the industry? In a rather overlooked paper, Romer (1993) suggests the adoption of a specific institutional design which is likely to address these various problems. The model of Romer is based on the establishment of investment boards within an industry, which are oriented towards the provision of a range of complementary capabilities that are financed by the means of a compulsory levy. Each board is specialized in the provision of one particular type of capabilities, such as university research, upstream equipment industry, technical standards or training. In this model, the compulsory levy helps to avoid the problem of free riding since all firms in the considered industry are de facto members of the club. What is produced through the boards are public goods, relevant and available to all; this way the monopolization issue is addressed. Above all, the boards compete to capture resources, and new boards can be freely set up as required. Thus, the model is based on the fundamental principle that every firm is free to decide how to allocate its funding- to either create new boards or to choose among competing boards; a solution to the disagreement issue.

A final strand of literature involves empirical analysis of Coasean institutions in the field of $R \& D$ and innovation. The greatest part of this literature focuses on one single form of club dedicated to the voluntary formation of R\&D clubs, designed to address the knowledge externality problem. The second smaller group of papers includes studies on institutions that need to respond to more diversified and complex needs in terms of industry specific public goods (not only R\&D). Typically, an industry association allows member firms to collectively fund the provision of a range of specific public goods such as the formation of specialized human capital, the development of specific technologies or the implementation of voluntary technical standards. Enhancing access to University research is another important goal for this kind of institution. Logically problems of collective action and coordination are even more complicated to solve than in the first case (of organizations devoted to R\&D only). Our paper enters this second category.

Weder and Grubel (1993) present the historical study of the watch-making industry in Switzerland. The companies set up an industrial association at the beginning of the 1900s. This association established the Swiss laboratory for horological research. In 1962, it created a new institute devoted to the development of the electronic watch movement, sponsored a number of schools with specialist training programmes and supported and maintained an apprenticeship scheme. The association not only finances industry-specific R\&D and training, it also provides efficient means for disseminating knowledge relevant to the operation of member firms.

A special issue of Research Policy (1996) — devoted to the problem of industrial modernization-offers a collection of case studies of Coasean Institutions, designed to provide industry-specific public goods. Kelley and Arora (1996) describe a group of leading companies - including both suppliers and users in the field of integrated circuits-which created a consortium for supplier training, established regional training centers to deal with quality control issues and cost-effective production methods for small suppliers. Ynnon (1996) develops the case of the plastics processing sector in the State of New York where companies have created the Society for Plastic Engineering, which deals with training and technology transfer. Sabel (1996) develops the American example of the National Institute for Standards and Technology which in the early 1990s established the Manufacturing Center Programmes. One example of an institution created within this programme is the Textile/Clothing Technological Corporation which began as technological development unit. Its mission was then broadened to include educational and demonstration activities. 
The association focuses most its research efforts on identifying and testing existing technologies and adapting them to textile manufacturing process.

A couple of interesting case studies deal with the US high tech consortium SEMATECH since it is a case of institutional evolution-within the space of Coasean solutions. SEMATECH started as the formation of a voluntary cooperative R\&D organizationinvolving the major US suppliers and users of semiconductor process equipment and materials. Since its foundation-as a club to internalize knowledge spillovers within a closed network of firms - SEMATECH has considerably expanded its field of operations towards other types of industry specific public goods. In many respects, it resembles then an industry association, diffusing information and best practice techniques, setting standards and coordinating generic research (Grindley et al. 1994, Bronwning et al. 1995).

Last but not least, in a book devoted to the emergence and development of the Swiss medical devices industry, Schlich (2002) shows the centrality of another industry association in the field of medical technologies. Six Swiss surgeons developed new methods to repair broken bones using internal fixations (plates and screws) and early functional exercise. They created their own company based in Davos $(\mathrm{CH})$-Synthes - that was in charge of $R \& D$, training and promotion of the new techniques all over the world. This case involves the creation of a private institution to solve the important coordination problems that arose as the new activity started to grow.

In each of these cases, institutional design strongly matters in order to deal with the various problems mentioned above (monopolization and competition, intellectual property regime, transaction costs) beyond the general principle of a voluntary association of firms created to secure the provision of the needed industry-specific public goods.

Finally one can note that the dichotomy between public finance and Coasean solutions has blurred boundaries. In particular, the State is involved to a certain degree in most Coasean cases. The State provides support through two channels: either through direct subsidies to cover some of the marginal costs of operations of the association or through competitive project grants as part of the business model of the association. We assume there is a Coasean institution when the first channel (direct subsidies) only cover a small fraction of the total transaction and operation costs of the association. This is therefore more a matter of degree than of sharp discontinuity.

With regard to this literature review, our paper provides two novelties. First, the case study highlights new organizational design elements that have proven to be successful in dealing with collective action and disagreement issues that are likely to arise within a club. This provides valuable results for both scholars and policy makers interested in analyzing and encouraging such institutions. Second, to the best or our knowledge, the paper provides the first empirical attempt to use innovation survey data to observe and measure Coasean institutions within a given national system of innovation.

\subsection{University-industry knowledge transfer}

In this paper, we focus on a particular type of industry specific public goods - those which involve university research, technologies, skills and services that are relevant for the SMEs of a given group of industries. These are resources that the SMEs strongly need but are unable to produce and maintain by themselves.

However, as amply demonstrated and discussed in academic literature, case studies and innovation surveys, direct transfers of knowledge between universities' science 
communities and SMEs are problematic to institutionalize. ${ }^{1}$ According to this literature, many factors generate significant difficulties for knowledge transfer between top scientists based in universities and SMEs. To identify only a few, we can mention the two following broad issues (Agraval 2001; Siegel et al. 2001; David and Metcalfe 2008; Foray and Lissoni 2010):

First, it is clear that the interests and motivation of professors on the one hand and SMEs on the other are very different (Callaert et al. 2008). One could approach this problem through the notion of "optimal quality of invention" (Foray and Lissoni 2010). Both academic research and SMEs are seeking "optimal quality". However, the optimum is not the same for both. From the point of view of academic research, optimal quality deals with the novelty gap or inventive step, elegance of the solution, importance and generality of the new knowledge. From the point of view of the SME, optimal quality deals with cost effectiveness, reliability of the new system, time to market, and existence of an effective supply for the various inputs of the new production function. This is a major tension. We could summarize it by contrasting a logic of basic and long-term research, which is what professors are interested in, and a logic of quick and dirty services, which is what SMEs need the most. Although this way of presenting this tension is somewhat extreme, it is nonetheless the reality for most SMEs. Thus, the mental mobilization and cognitive focus is on different aspects of an inventive activity. In the worst case, the gap will never be filled. In the best case, the involvement of faculty in the post-invention process to develop the technology is key to overcome the tension about "optimal quality" (Zucker and Darby 1996, 1998). However, the existence of different norms and cultures, which are highly amplified in the case of SMEs [as compared to large companies, which recruit researchers with some academic background precisely to improve the connections to academia (Cockburn et al. 1999)], makes it difficult to achieve this involvement of academic researchers.

Secondly, there is a scale issue in that the Transfer of Technology Offices of universities are not that interested in talking with one single SME about one specific problem. We know that important determinants of R\&D productivity include the possibility to realize economies of scale and scope, and to exploit potential internal spillovers among various projects (Henderson and Cockburn, 1996) — things that are unlikely to happen in the case of a research partnership with one particular SME which is looking for a solution to one particular problem.

Representative data for Switzerland illustrates the concrete consequences of such difficulties. While in the period 2002-2004 about 19\% of the small (less than 50 employees) companies in Switzerland are involved in some kind of transfer of knowledge and technologies with universities, the respective share dropped to 16\% in the period 2008-2010 (SBFI, 2016; Arvanitis et al. 2012, 2016). These data are important to consider since Switzerland is a country in which SMEs are usually viewed as the backbone of the economy and show rather good performance in terms of innovation and competitiveness (Foray and Hollanders, 2015). Moreover, Arvanitis et al. (2008) found that transfer activities with universities improve the innovation performance of Swiss firms, especially if the ties with universities are strong (Arvanitis and Woerter, 2009).

Given these arguments and evidence, one seeks to identify institutions which can support knowledge and technology transfer in an efficient manner in the case of small

\footnotetext{
1 The 'SME' category considered here of course does not include just-off campus firms founded by academics.
} 
companies. We assume that a Coasean institution-as conceptualized and analyzed above — can provide an interesting organizational solution to this kind of problem.

\section{Empirical methods}

We pursue two different types of empirical methods to investigate the significance of Coasean institutions for knowledge transfer and the innovation performance of SMEs.

In a first step, we conducted thus a case study. Inspire $A G$ provides a platform for the knowledge and technology transfer between a top university (ETHZ) ${ }^{2}$ and SMEs in the field of machine tool and micro-engineering. It has two remarkable features which make it an interesting case to study.

First, the modus operandi of the platform seems to represent an interesting solution for some of the problems arising from the very process of knowledge transfer between a top research university and small companies.

Second, the historical origin of the platform provides an interesting example of emergence and development of a Coasean institution-i.e. of the creation of a private institution by the economic agents themselves in order to solve the collective action problem raised by the provision of specific public goods (here technologies and knowledge).

In the conclusion of the case study, we argue that the particular origin of the platform has strongly influenced the design of its operational modes, so that the two features are strongly interrelated.

In a second step, we investigate if the case study is a model for improving the innovation performance of SMEs in Switzerland. Based on a representative firm sample, we identify firms that are exposed to such an ecosystem, and investigate econometrically if their innovation performance is significantly better compared to non-exposed firms.

\subsection{Case study}

\subsubsection{History-Coasean entrepreneurs and responsive professors}

The history of Inspire is clearly one of the formations and development of a Coasean institution in the area of knowledge and technology transfer. ${ }^{3}$ At the turn of the millenium, one important research institute at ETHZ - in the field of machine tools and production technologies - was about to close, because of the retirement of a professor. In the same period, the top management of the university was very excited about the revolution in life sciences and wanted to allocate most of its strategic funds to the emerging field of biotechnology. The fact that both recently nominated presidents (of ETHZ and EPFL) at the time were life scientists explains these strategic priorities of the two federal institutes of technology.

\footnotetext{
${ }^{2}$ Eidgenössische Technische Hochschule Zürich (ETHZ). The ETHZ is regularly ranked among the top ten European Universities. Together with EPFL (Ecole Polytechnique Fédérale de Lausanne) and a few research institutes, it forms the ETH domain, which is mainly funded by the Federal State and represents one major component of the Swiss research and innovation system.

${ }^{3}$ We greatly acknowledge the openness and help of Inspire: Prof. Wegener (ETHZ), Prof. Meboldt (ETHZ), Dr. Krebser (CEO), Dr. Zogg (head of a research group) and Dr. Weiss (head of a research group). We also benefited from the opportunity provided by Inspire to visit SMEs involved in Inspire activities such as Alpa and Agathon (both located in the German speaking part of Switzerland).
} 
Indeed, the initial idea of the top management of ETHZ was to transfer the whole machine tool and production technology activities to the universities of applied sciences located in the Zürich and St. Gallen area. (Now, approximately twenty years later, with the whole disruptive and productivity potential of industry 4.0, additive manufacturing and Internet of Things, it can be said that this was potentially a major strategic failure!) Worried about the new ETHZ strategy, two SMEs (Schneeberger and Starrag-Heckert) approached the university's top management as well as the Industrial Association of the Machine Tool Industry (SwissMem) to propose a different strategic option. They proposed that ETHZ recruited a new professor and continued running the Research Institute of Machine Tool and Production Technologies. Moreover, they suggested to create a new company that worked at the interface between ETHZ and the SMEs, to maximize knowledge and technology transfer from the research institute to the SMEs. The basic funding during the first years of the operation, which was used for building the company, was provided by SMEs, the Industry Association and a federal public subsidy. ETHZ management accepted this entrepreneurial initiative under the condition that the new professor was to be a top scientist and, as such, not involved in the daily interactions with the SMEs. This restriction eventually led to the idea of research groups being different and autonomous from academic institutes and activities, while at the same time keeping strong connections with them.

Prof. Wegener, the new ETHZ professor recruited to lead the institute was (and still is) a top scientist and a great academic entrepreneur, who is highly committed to technology transfer. He very quickly built up several research groups within Inspire. Many SMEs of the machine tool industry joined Inspire and became shareholders of the company. (Today about 25 Swiss SMEs of the machine tool and production technologies industry are shareholders of Inspire). When other ETHZ professors joined Prof. Wegener as academic partners, further research groups were created.

Inspire is a rather small organization, composed of 6 ETHZ professors, 60 employees (mostly senior scientists and graduate students) and 10 research groups. In 2017, about 70 projects of knowledge and technology transfers were carried out.

The organization's turnover reached CHF 12.0 Mio. in 2018. About $60 \%$ of its turnover comes from projects with SMEs. Many of these projects (28\% of the turnover) are funded within the framework of Switzerland's main innovation policy program (the CTI project support scheme funds the research partner of the SME directly ${ }^{4}$ ). Most of the other projects are directly funded by the SMEs themselves (28\% of the turnover). $27 \%$ of the turnover is Government support and 6\% is ETHZ contribution in kind (time spent by the six professors on supervision and coordination tasks).

\subsubsection{Organisational structures and operational processes}

The insert below provides a stylized representation of the organization of Inspire-involving three parties: academic research at ETHZ, the Inspire Research Group structure, and the SMEs.

\footnotetext{
${ }^{4}$ CTI stands for Commission for Technology and Innovation.
} 


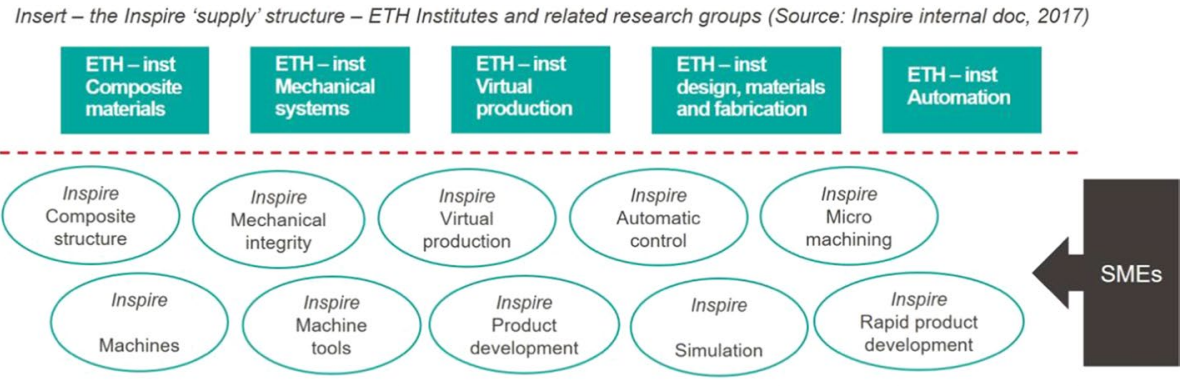

ETH-inst

Machine tools \&

manufacturing

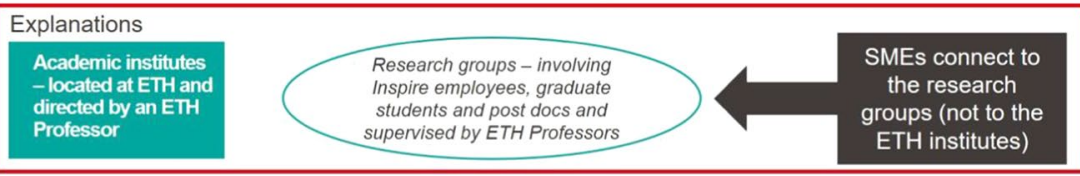

The first key point is that ETHZ professors are not directly involved in the daily work of the platform. They can be if they want to but their participation is not necessary for the daily operations. Instead of a direct involvement, they provide critical resources, such as ideas and insights, and above all manpower, such as Master and PhDs students as well as post-doctoral assistants. The platform consists of different (thematic) research groups, which are composed of engineers and researchers who are not the professors themselves but Inspire employees as well as graduate and post-doctoral students. The SMEs use the platform for projects and/or problems, and the platform itself works as a "market" where potential partners meet to decide about new activities in terms of knowledge and technology transfer (see insert above).

It can be expected that this kind of flexible and "market-based" arrangement (reminding us of the Paul Romer (1993) solution in some aspects) minimizes the difficulty of maximizing knowledge transfers between universities and SMEs.

First, the divergence of motivation and interest between professors and SMEs is no longer a problem since professors stay in the background, so to speak, and the main contact partners of the SMEs are the research groups. These represent the locus where academic ideas and competences meet SMEs problems and needs, and the parameters of invention's "optimal quality" gradually converge. In a sense, thanks to this structure, Professors and academic scientists are "only connected", to paraphrase the title of a paper by David and Metcalfe (op.cit): the organizational structure of Inspire respects the division of labour between academia and industry and helps to avoid overloading Professors as suppliers of innovation services.

Second, the coordination between academic scientists, the Inspire research groups and the SMEs involves a mix of transactions and interactions - as well defined and distinguished by Antonelli and Patrucco (2016). In most cases the collaboration between the three parties is long-standing and goes from one project to another. While the research collaboration is always formalized on a contractual basis, the whole process of knowledge generation and transfer is made of many personal and socially based forms of coordination. 
Such a mix of transaction and interaction is a clear factor of success. We know from a lot of empirical studies (for instance Thursby and Thursby, 2003) that the most important mechanism for knowledge transfer from academic scientist to small companies is the one-on-one approach based on personal contact-which is what happens all the time in the framework of the Inspire research groups. Interactions involve also training processes. Within Inspire, training is bidirectional-towards the SMEs who are exposed to young engineers who have acquired the most recent technological knowledge and also towards the $\mathrm{PhD}$ students and postdocs who accumulate experience by interacting with SMEs and are funded through Inspire activities.

Third, although SMEs proceed individually to identify a research group and propose a project, economies of scale and scope in knowledge production and internal informational spillovers take place in any case, thanks to the organizational structure of Inspire. Within each research group, various related projects are run in parallel, and Inspire scientists and engineers are in a position to exploit potential synergy and economies of scope among projects. Inspire therefore works as a mechanism that aggregates projects within each research group, which then creates opportunities for realizing economies of scale and scope and internal spillovers.

\section{Insert-quotation by ETHZ Pr. Mirko Merboldt on scale, scope and spillovers within his research group}

In many cases, we are running individual projects which have strong similarities. This provides opportunities for sharing knowledge between, and cumulating information among the members of the research group who are working on different projects. This also allows the use of the same research tool to run experiments in various projects. Projects remain bilateral_linking a research group to a company-but many resources are shared at the research group level.

Pr. Merboldt—personal interview-October 30th 2017—at ETHZ.

Fourth, the organizational structure of Inspire, which makes the research groups the central connection between the academic scientists and the SMEs, also supports the economic discovery of potentially profitable business models. One very successful research group - the Institute for Rapid Product Development-was spinned off from Inspire because its selling proposal became both very successful and very focused on services, and therefore no longer needed ETHZ academic background. A further two spin-offs have emerged, based on the same rationale: the orientation of the research group towards services to SMEs no longer justified the involvement of ETHZ and allowed the discovery and testing of interesting new business models. At the same time as new research opportunities and challenges for this industry emerge, new research groups are created. The most recently created research groups (between 2014 and 2016) deal with additive manufacturing and industry 4.0. This double movement of spinning-out some maturing activities and constructing new ones highlights the capacity of the platform to adjust its supply to new opportunities both in terms of research and business models for SMEs. Rapid and accurate supply response can be considered a property of a system of strong connections between the three components-professors, SMEs and research groups. The research groups represent the flexible component within the whole system.

The organizational principle of autonomous research groups-different from but connected to professors - has many advantages, as explained above, and makes Inspire a rather unique model. For instance, it is different from the German "Fraunhofer Institute", where professors have a double-affiliation (University and Fraunhofer) and are much more involved in the daily operations of knowledge transfer and, as a consequence, are loosing 
their academic status. Inspire is also different from research and technology contract organizations, which usually have a much weaker academic background and weaker connections.

\subsubsection{The Coasean logic of Inspire}

The next question to address is about the specific Coasean institutional logic of Inspire. We highlighted above the scale problem that is likely to impede the development of research partnerships between a prestigious University and SMEs. The University will require a potential critical mass of projects to start a research partnership with SMEs and Inspire precisely has been created to facilitate the access of ETHZ to a larger pool of projects than what could be offered by one single SME.

In other words, the collective action of SMEs is needed in order to cooperate with universities. Inspire provides a coordination mechanism necessary to collectively build an aggregate demand for technologies and other services so that a positive supply response emerges from the university, and lasting relationships are developed. This means that Inspire falls in a specific category of the Coasean model. The Coasean model suggests that the existence of externalities induce the creation of private institutions which internalize the externalities. Then the classical case is the one where externalities are coming from $R \& D$ and induce the creation of a specific category of institutions-the so-called $R \& D$ consortium. In the Inspire case, the main externalities at stake should not be assimilated to R\&D spillovers. They are instead of the form of network externalities: as far as SMEs are concerned in technology transfers, the number of potential partners has an influence on the willingness of the University to develop such partnerships with them. A large quantity of projects (or partners) facilitates scale, scope and internal spillovers, increases R\&D productivity and makes therefore such research partnership more attractive for the University as well as for the individual Professors (who can engage in long-standing collaborations with industrial partners). This is this network externality which is captured by Inspire: the SMEs have built a club not necessarily to share knowledge among themselves but to build a common bridge to facilitate their (individual access) to the academic research. As a specific case of the Coasean framework, involving network externalities, Inspire can also be described as an innovation platform—as recently analyzed by Antonelli and Patrucco (op. cit.).

\subsubsection{Discussion}

Considering the various issues discussed above, which can make it difficult to create and operate a Coasean institution, it should be mentioned how Inspire provides solutions, thanks to its organizational design and its Coasean logic as well as the historical tradition of high-level managerial capabilities in the Swiss industry.

For instance, the incentives to form a club were strong and transaction costs were minimized thanks to a long tradition of collective actions and coordination among SMEs-a general historical feature that characterizes most industries in Switzerland. While Inspire is a very recent example, the Swiss business history is full of other cases of SMEs forming a club spontaneously to provide the industry-specific public goods required. Weder and Grubel (op.cit.) highlighted cases of the watch industry and chemical industries in particular, where such institutions were created by companies quite early on in their history. Schlich (2002) studied the case of a Coasean institution in the Swiss medical technology sector: six Swiss surgeons developed new methods to repair 
broken bones using internal fixations (plates and screws) and early functional exercise. They created their own company based in Davos $(\mathrm{CH})$ - Synthes - that was in charge of $\mathrm{R} \& \mathrm{D}$, training and promotion of the new techniques all over the world. This case involves the creation of a private institution to solve the important coordination problems that arose as the new activity started to grow.

Several other cases in various industries were mentioned by Breiding and Schwarz (2011). We already referred to Ghemawat (op.cit.) arguing that good management, instead of policy, can reduce potential market failures because "good" managers appreciate the "private" value (i.e. for their own companies) of collective and coordination actions to solve a wide range of public goods problems. Good management at firm level is therefore certainly a key element in the Inspire story. Here we touch upon the limits of empirical economics, as a disciplinary field, to explain innovation performance: good management involves things like value and culture that are very difficult to measure by definition, and the emergence of which is also very difficult to understand, at least within the boundaries of our discipline.

Potential disagreements about what the club should provide in terms of specific public goods are strongly minimized thanks to Inspire's ingenuous organizational structure. There is a minimal level of consensus required among firms which can be summarized as: "ETHZ can make useful things for us". But beyond that point, any potential disagreement among firms can be solved by the option for each firm to proceed individually with a research group. In the same vein, there are very few intellectual property conflicts given the fact that most projects are bilateral (does not involve more than one company). Recall that the main goal of Inspire is not about sharing knowledge among competing SMEs but rather building collectively a large demand for University research. Cumulative learning and knowledge sharing do occur but at the research group level. Therefore, cumulative learning is not a cause of conflict while it represents an important source of R\&D productivity (see insert above).

Monopolization is an issue as Inspire does not cover the whole industry, as opposed to the Romer model where all firms in the industry are obliged to pay a tax, de facto making them part of the club. However, a compulsory tax somewhat corrupts the Coasean nature of the institution (even if in the firms in the Romer model are free to allocate their tax to any kind of "public good"). In the case of Inspire, nothing prevents a new company to enter the club. The new company needs to contribute to the funding of Inspire as a shareholder, while the existing members (even potential rivals) have no power or right to block any entry. Entry conditions are discussed and decided between the new potential member and the Inspire management.

To summarize our case study, Inspire offers an example of a specific case of a Coasean institution (the logic of which is about capturing network externalities). The goal of Inspire is indeed to offer a large number of potential projects to make research partnerships with SMEs attractive for the University. However, a large quantity of projects with SMEs could have some side effects for academic research as University Professors could become too involved in providing innovation services. This is why, the institutional logic is coupled with an ingenuous organizational structure: establishing an intermediary structure between academic research and SMEs - the research groups-allows to invent a particular connection which respects the division of labor between academia and industry (David and Metcalfe, op.cit.) and offers a specific locus for cumulative learning, while preserving the collective of SMEs from the usual conflicts (regarding IPR) and disagreements (on research objectives) which often characterize any $R \& D$ consortium. 
It is thus important to see the strategic complementarity between these two featuresthe organizational structure (the creation of research groups as an intermediary level) and the specific Coasean logic (the capture of network externalities), as there is a value of coupling them within the same entity.

\subsection{Econometric estimations}

\subsubsection{Data}

In the main econometric estimations, we use survey data about knowledge and technology transfer activities between universities and companies. The survey has been carried out in 2018 by the ETH Zürich, KOF Swiss Economic Institute. It was commissioned by the Swiss state secretary for education, research, and innovation (SERI) and provides the official data on transfer activities of enterprises. The survey is based on a stratified random sample of companies with more than 5 employees. The sample has been drawn from the Swiss business census provided by the Federal Statistical Office. Stratification refers to 34 (two-digit) industries and, within each industry to three firm-size classes. The survey is not compulsory for Swiss firms, however, the response rate is quite satisfactory, it amounts to $26 \%$ (see Beck et al. 2019). The authors are part of the team that collects the data and therefore have an in-depth knowledge not only about the questionnaire, but also about the survey process, the response behavior of firms, the recall action, and the nonresponse analysis. The recall action is a very important part of the survey, essentially contributing to the quality of the data and the response rate. It should not only guarantee a high response rate but also consider an equal distribution of the response rate across the cells of the sample plan. ${ }^{5}$ For our main estimations we can draw on firm-level information for 1343 companies.

The survey contains specific questions about the type of public transfer partners. It shows a list of institutions that does not only include the ETH Zurich, EPF Lausanne, universities of applied sciences or cantonal universities, but also technology competence centers that are listed as Art. 15 RIPA (Federal Act on the Promotion of Research and Innovation) organizations. The question about the competence centers represent the organizational form of Coasean institutions and even lists Inspire AG as an example (see also the paragraph on the measurement of Coasean institutions below).

\subsubsection{Descriptive information}

Tables 1 and 2 present the descriptive information of the data used in the main econometric estimations. Given that we are considering all companies with more than 5 employees the average sales of new products (CHF 166) and modified products (CHF 545) are very low. However, if we restrict the sample to only innovative companies, the average sales of new and modified products increases to CHF 186'850 and CHF 999'640, respectively. Moreover, we see that about $25 \%$ of the companies in our sample have transfer contacts with universities and 3\% have transfer contacts with Coasean Institutions. The average firm in the

\footnotetext{
5 There are 34 industries and within each industry 3 firm-size classes (small, medium, large). Hence, there are 102 cells $(34 * 3)$. For more information about the surveys, see Beck et al. 2019.
} 
Table 1 Summary statistic

\begin{tabular}{lllllr}
\hline & Obs & Mean & SD & Min & Max \\
\hline Innosales (ln) & 1,343 & 5.67 & 7.20 & 0.00 & 22.17 \\
Innosales new (ln) & 1,250 & 5.11 & 7.14 & 0.00 & 22.62 \\
Innosales modified (ln) & 1,331 & 6.30 & 8.05 & 0.00 & 23.13 \\
Coasean institution (Art.15) & 1,343 & 0.03 & & 0.00 & 1.00 \\
R\&D expenditures (ln) & 1,343 & 3.56 & 5.82 & 0.00 & 21.64 \\
Transfer activities & 1,343 & 0.25 & & 0.00 & 1.00 \\
Size (ln) & 1,343 & 3.86 & 1.40 & 0.69 & 9.48 \\
Higher education (ln) & 1,343 & 1.93 & 1.45 & 0.00 & 8.05 \\
\hline
\end{tabular}

Table 2 Correlations

\section{(1)}

(2)

(3)

(4)

(5)

(6)

(7)

(8)

(1) Innosales (ln)

(2) Innosales new (ln)

(3) Innosales modified (ln)

(4) Coasean institution (Art.15)

(5) R\&D expenditures (ln)

(6) Transfer activities

(7) Size (ln)

(8) Higher education (ln)

\subsection{0}

$0.997 \quad 1.000$

$0.994 \quad 0.995$

$0.205 \quad 0.201$

$0.615 \quad 0.618$

$0.370 \quad 0.370$

$0.338 \quad 0.341$

0.349

0.352

1.000

0.196

0.607

0.367

0.336

0.345
1.000

$0.308 \quad 1.000$

$\begin{array}{lll}0.286 & 0.486 \quad 1.000\end{array}$

$\begin{array}{llll}0.149 & 0.330 & 0.275 & 1.000\end{array}$

$0.141 \quad 0.352$

$0.279 \quad 0.825$

sample has 47 employees (full-time equivalent (FTE)), and the number of employees with a higher education amounts to 6.9 (FTE) on average.

Table 2 presents the correlations between the variables in the main model. Naturally, there is a strong correlation between the different types of innovative sales (new products and modified products), since innovative companies usually aim at both, developing new products and permanently modifying the existing ones. Also interesting is the strong positive correlation between the innovation variables and the variable for transfer contacts with the Coasean institutions; the correlation is 0.205 . As expected, the correlations between the dependent variables and $R \& D$ expenditure are also very strong.

\subsubsection{Model specification and estimation methods}

To investigate the effectiveness of Coasean institutions, we estimate the following equation as our main model:

$$
y_{i}=\beta_{0}+\beta_{1} C_{i}+\beta_{2} r n d_{i}+\beta_{3} r n d_{i} * C_{i}+X_{i} \gamma+\pi_{j}+\varepsilon_{i}
$$

where

$$
y_{i t} \epsilon\left\{\text { innosales }(\ln )_{i t}, \text { innosales new }(\ln )_{i t} \text {, innosales modified }(\ln )_{i t}\right\}
$$

$y_{\mathrm{it}}$ is the dependent variable, which measures the innovation performance of the focal firm by the logarithm of the sales of innovative products (innosales(ln)), the logarithm of the 
sales of new products (innosales new $(\ln )$ ) and the logarithm of the sales of essentially modified products (innosales modified(ln)). These types of measures represent different degrees of innovation depth. "Innosales new" represents more advanced innovative products and "innosales mod" represents less advanced innovations. "Innosales" is the sum of both types of innovations. ${ }^{6}$ This information stems from the above mentions survey. Innovative products refer to products and services newly introduced in the last three years (2015-2017). Their sales are then measured in the last of the 3 years (2017).

The most important explanatory variable is C. It indicates whether a company had transfer contacts with Coasean institutions, like INSPIRE, between 2015 and 2017. The absorptive capacity of a company (Cohen and Levinthal 1989, 1990) is an essential input factor for the innovation performance of a company. It does not only represent the innovation effort of a company, but also the ability to understand, transfer, and apply external knowledge in-house. We approximate the absorptive capacity of a company with its (log of) $\mathrm{R} \& \mathrm{D}$ expenditures (rnd). By interacting these two variables ( $\mathrm{C}^{*} \mathrm{rnd}$ ), we investigate, whether the absorptive capacity of a company is an essential (internal) prerequisite for successful cooperation with Coasean institutions.

Moreover, we have a rich control vector $(\mathrm{X})$ comprising a proxy for other transfer activities with public research institutions (transfer activities), the size of a company, and the education level of the employees. The variable for the transfer activities of a company is a binary variable. It receives the value 1 if a company has transfer contacts with public research institutions and zero otherwise. We define transfer activities in a broader sense. It comprises informal contacts, the use of public research infrastructure (e.g. joint laboratories), education related transfer forms (e.g. support dissertations at universities, industrial sabbaticals), R\&D collaboration, and consulting activities. Bozeman (2000) developed such a broad concept of transfer activities, which has also been applied in Arvanitis et al. (2008) or Arvanitis and Woerter (2009). The size of a company is measured by the logarithm of the number of employees in full-time equivalents (FTE) and the education level refers to the number of FTE with a degree higher than vocational training. We also use two-digit industry-dummies to control for unobserved industry specific heterogeneity and we present heteroscedasticity robust standard errors in all estimations.

\subsubsection{Identification issues}

Even though we have a rich control vector that accounts for the theoretically most important factors for determining the innovation performance of a firm (see Cohen 2010), ${ }^{7}$ we cannot exclude identification issues. Since the information about Coasean institutions (Art. 15 Institutions) are only available in one cross section, we cannot apply panel econometrics to address unobserved heterogeneity and reverse causality.

\footnotetext{
${ }^{6}$ Please note that the number of observations for the "innosales" estimation is different from the "innosales mod" and "innosales new" estimations. The reasons are missing values for both types of innovative sales.

7 These are, for instance, size and size related factors like R\&D expenditures, skill level of the firm's employees, transfer activities, and sector fixed effects that control for appropriability conditions and the technological potential.
} 
Table 3 Base estimations (all companies)

\begin{tabular}{llll}
\hline Variables & $(1)$ & $(2)$ & $(3)$ \\
& OLS & OLS & OLS \\
& Innosales (ln) & Innosales new (ln) & Innosales modified (ln) \\
\hline Coasean Institution (Art.15) & $-1.108(0.872)$ & $-1.681^{*}(0.900)$ & $-2.107 * *(0.948)$ \\
R\&D expenditures (ln) & $0.479^{* * *(0.041)}$ & $0.510^{* * *}(0.041)$ & $0.503^{* * *}(0.044)$ \\
Transfer activities & $1.508^{* * *}(0.466)$ & $1.461^{* * *}(0.479)$ & $1.763^{* * *}(0.517)$ \\
Size & $0.580^{* * *}(0.203)$ & $0.543^{* * *}(0.204)$ & $0.682^{* * *}(0.228)$ \\
Higher education (ln) & $0.343^{*}(0.200)$ & $0.456^{* *}(0.204)$ & $0.496^{* *}(0.226)$ \\
Constant & $2.272(4.323)$ & $2.972(4.904)$ & $3.717(5.987)$ \\
Observations & 1,343 & 1,321 & 1,423 \\
Industry fixed effects & Yes & Yes & Yes \\
$\mathrm{R}^{2}$ & 0.428 & 0.435 & 0.385 \\
$\mathrm{~F}$ & 49.89 & 49.85 & 42.36 \\
\hline
\end{tabular}

Heteroscedasticity robust standard errors in brackets. ${ }^{* * *} p<0.01, * * p<0.05, * p<0.1$

\subsubsection{Measurement of the Coasean institution}

The above-mentioned company survey includes a question about the public partners of the transfer activities. We have asked, with which Swiss scientific institutions knowledge transfer activities took place in the last three years. In addition to a number of other institutions, the companies could also indicate whether they work with Inspire or other technology competence centers, which are supported according to Art. 15 RIPA. ${ }^{8}$ The answer to this question tells us whether companies use Coasean institutions for knowledge and technology transfer. It is a binary variable that receives the value one if this is the case and zero otherwise.

\subsection{Results}

The main estimation results are presented in Tables 3,4,5,6. The moderating effect of the Coasean institutions on the performance effects of in-house R\&D activities is shown graphically in Figs. 1,2,3,4.

\subsubsection{All companies}

The base estimations for all companies (Table 3) shows that Coasean institutions tend to have a negative effect on the sales with new products and modified products, whereas R\&D expenditures and transfer activities in general show a significant and positive relationship with all types of innovative sales. All estimates have a high $\mathrm{R}^{2}$; the estimations explain between 38 and $43 \%$ of the variance of the dependent variables.

${ }^{8}$ See https://www.admin.ch/opc/en/classified-compilation/20091419/index.html. 
Table 4 Moderating effects of Coasean Institutions (all companies)

\begin{tabular}{llll}
\hline Variables & $(1)$ & $(2)$ & $(3)$ \\
& OLS & OLS & OLS \\
& Innosales (ln) & Innosales new (ln) & Innosales modified (ln) \\
\hline Coasean Institution (Art.15) & $-20.136^{* * *}$ & $-20.596^{* * *}$ & $-21.434^{* * *}$ \\
& $(6.310)$ & $(6.185)$ & $(7.495)$ \\
R\&D expenditures (ln) & $0.477^{* * *}$ & $0.508^{* * *}$ & $0.501 * * *$ \\
& $(0.041)$ & $(0.041)$ & $(0.044)$ \\
R\&D expenditures (ln)*Coasean & $1.304^{* * *}$ & $1.299^{* * *}$ & $1.333^{* * *}$ \\
Institution (Art.15) & $(0.406)$ & $(0.395)$ & $(0.489)$ \\
Transfer activities & $1.557^{* * *}$ & $1.512^{* * * *}$ & $1.807 * * *$ \\
& $(0.467)$ & $(0.479)$ & $(0.518)$ \\
Size & $0.569^{* * *}$ & $0.533^{* * *}$ & $0.672 * * *$ \\
& $(0.203)$ & $(0.204)$ & $(0.228)$ \\
Higher education (ln) & 0.321 & $0.435^{* *}$ & $0.478^{* *}$ \\
& $(0.201)$ & $(0.204)$ & $(0.226)$ \\
Constant & 2.374 & 3.069 & 3.801 \\
& $(4.319)$ & $(4.901)$ & $(5.985)$ \\
Observations & 1343 & 1321 & 1423 \\
Industry fixed effects & Yes & Yes & Yes \\
$\mathrm{R}^{2}$ & 0.431 & 0.438 & 0.387 \\
F & 55.20 & 57.85 & 44.92 \\
\hline
\end{tabular}

Heteroscedasticity robust standard errors in brackets. ${ }^{* * *} p<0.01, * * p<0.05, * p<0.1$

Furthermore, we found that in-house $R \& D$ is a necessary condition for the success of Coasean institutions (Table 4). The interaction effect between R\&D expenditures and Coasean institutions is significant and positive. Coasean institutions increase the positive performance effects of R\&D expenditures significantly. In quantitative terms we see that a $1 \%$ increase in $R \& D$ expenditures seems to increase the innovative sales by about $0.5 \%$. If we consider Coasean Institutions (Table 4 ), the marginal effect increases to about 1.8 , meaning that a one percent increase in the $R \& D$ expenditures tends to increase the innovation performance by $1.8 \%$. Since these results may be influenced by unobserved heterogeneity, they must be interpreted with caution. We do not claim causality of the effects.

Figures 1 and 2 present the marginal effects of the interaction term. We see that considerable R\&D expenditures are necessary to benefit from Coasean Institutions. On average for all companies and for all types of innovative products (Fig. 1), we see that performance effects are visible if the R\&D expenditures are around $40 \mathrm{Mio}$. CHF; for the sales with new innovative products of a company, the absorptive capacity-measured by its R\&D expenditures-needs to be even higher (Fig. 2). 
Table 5 Base estimations (SMEs)

\begin{tabular}{|c|c|c|c|}
\hline \multirow[t]{3}{*}{ Variables } & (1) & (2) & (3) \\
\hline & OLS & OLS & OLS \\
\hline & Innosales $(\ln )$ & Innosales new (ln) & $\begin{array}{l}\text { Innosales } \\
\text { modified } \\
(\ln )\end{array}$ \\
\hline \multirow[t]{2}{*}{ Coasean Institution (Art.15) } & -1.977 & $-2.709 * *$ & $-2.841 * *$ \\
\hline & $(1.258)$ & $(1.288)$ & $(1.362)$ \\
\hline \multirow[t]{2}{*}{ R\&D expenditures (ln) } & $0.498 * * *$ & $0.537 * * *$ & $0.527 * * *$ \\
\hline & $(0.046)$ & $(0.045)$ & $(0.048)$ \\
\hline \multirow[t]{2}{*}{ Transfer activities } & $1.658 * * *$ & $1.417 * * *$ & $1.737 * * *$ \\
\hline & $(0.496)$ & $(0.512)$ & $(0.551)$ \\
\hline \multirow[t]{2}{*}{ Size } & $0.622 * * *$ & $0.618 * * *$ & $0.768 * * *$ \\
\hline & $(0.213)$ & $(0.214)$ & $(0.240)$ \\
\hline \multirow[t]{2}{*}{ Higher education (ln) } & 0.321 & $0.454 * *$ & $0.473 *$ \\
\hline & $(0.214)$ & $(0.217)$ & $(0.241)$ \\
\hline \multirow[t]{2}{*}{ Constant } & 2.133 & 2.637 & 3.382 \\
\hline & $(4.356)$ & $(4.946)$ & $(6.030)$ \\
\hline Observations & 1,179 & 1,162 & 1,250 \\
\hline Industry fixed effects & Yes & Yes & Yes \\
\hline $\mathrm{R}^{2}$ & 0.396 & 0.404 & 0.360 \\
\hline $\mathrm{F}$ & 36.02 & 34.06 & 32.72 \\
\hline
\end{tabular}

Heteroscedasticity robust standard errors in brackets. $* * * p<0.01, * * p<0.05, * p<0.1$. SMEs refers to companies with less than 250 employees

\subsubsection{SMEs}

The effects are quite different for SMEs. ${ }^{9}$ Although we see-compared to all companiesa very similar base effects of $R \& D$ expenditures with a coefficient of around 0.5 (see Table 5), the meaning of Coasean institutions is considerably larger. In Table 6 we see that Coasean institutions might increase the marginal effect to about 3, meaning that an increase of R\&D expenditures by $1 \%$ is related to an increase of the innovative sales by about $3 \%$. We hardly see any differences between new and essentially modified products. This suggests that in particular the innovation performance of smaller companies benefits from Inspire and similar Coasean Institutions (CI).

Figures 3 and 4 also show that the amount of R\&D expenditures is considerable smaller for SMEs in order to benefit from Coasean Institutions; it is about 5 Mio. CHF for all types of innovative products and about 10 Mio. CHF for significantly increasing the sales of new products. Also these results may be influenced by unobserved heterogeneity and they must be interpreted with caution.

In the overall view of the results, it is above all SMEs with considerable R\&D expenditure and the associated high absorptive capacity that benefit from these institutions. The effect hardly differs according to the type of innovations.

9 SMEs are small and medium-sized companies with less than 250 employees. 
Table 6 Moderating effects of Coasean Institutions (SMEs)

\begin{tabular}{llll}
\hline Variables & $(1)$ & $(2)$ & $(3)$ \\
& OLS & OLS & OLS \\
& Innosales (ln) & Innosales new (ln) & Innosales modified (ln) \\
\hline Coasean Institution (Art.15) & $-33.428^{* * *}$ & $-32.350^{* * *}$ & $-38.594 * * *$ \\
& $(7.697)$ & $(7.589)$ & $(7.780)$ \\
R\&D expenditures (ln) & $0.496^{* * *}$ & $0.535^{* * *}$ & $0.525^{* * *}$ \\
R\&D expenditures (ln)*Coasean & $(0.045)$ & $(0.045)$ & $(0.048)$ \\
Institution (Art.15) & $2.317 * * *$ & $2.188^{* * *}$ & $2.633^{* * *}$ \\
Transfer activities & $(0.537)$ & $(0.521)$ & $(0.531)$ \\
& $1.683 * * *$ & $1.441^{* * *}$ & $1.764 * * *$ \\
Size & $(0.496)$ & $(0.512)$ & $(0.550)$ \\
& $0.613 * * *$ & $0.614 * * *$ & $0.759^{* * *}$ \\
Higher education (ln) & $(0.213)$ & $(0.214)$ & $(0.240)$ \\
Constant & 0.320 & $0.446^{* *}$ & $0.470 *$ \\
Rbservations & $(0.214)$ & $(0.217)$ & $(0.241)$ \\
Industry fixed effects & 2.177 & 2.673 & 3.431 \\
F & $(4.355)$ & $(4.946)$ & $(6.030)$ \\
\hline
\end{tabular}

Heteroscedasticity robust standard errors in brackets. ${ }^{* * *} p<0.01,{ }^{*} * p<0.05,{ }^{*} p<0.1$. SMEs refers to companies with less than 250 employees

\section{Conclusions and policy implications}

We pursued two different empirical approaches in order to investigate the meaning of Coasean institutions in Switzerland for the innovation performance of firms. First, we conducted a comprehensive case study dealing with a unique institutional experiment-Inspire $A G$. On the one hand, it provides a good example of a private institution created by several SMEs in order to support the provision of industry-specific public goods (in this case applied research and technological services which are relevant to a set of inter-connected industries) and, on the other hand, it highlights particular organizational mechanisms and structures, which seem rather effective for coping with a series of problem arising from university-SMEs research relationships.

Secondly, we performed econometric estimations to determine the general validity of the case study results. For this purpose, we performed econometric calculations on two different data sets. First, we used data from a survey on transfer activities of companies with public research institutions in Switzerland. Although this dataset contains information on transfer activities with Inspire and similar organizations, it only contains crosssectional information that does not allow for further estimation procedures to take into account unobserved heterogeneity. Therefore, we perform a series of robustness tests based on another data set. These data come from the Swiss Innovation Survey (SIS) covering the time period 1999-2015. The SIS is based on a stratified random sample of 


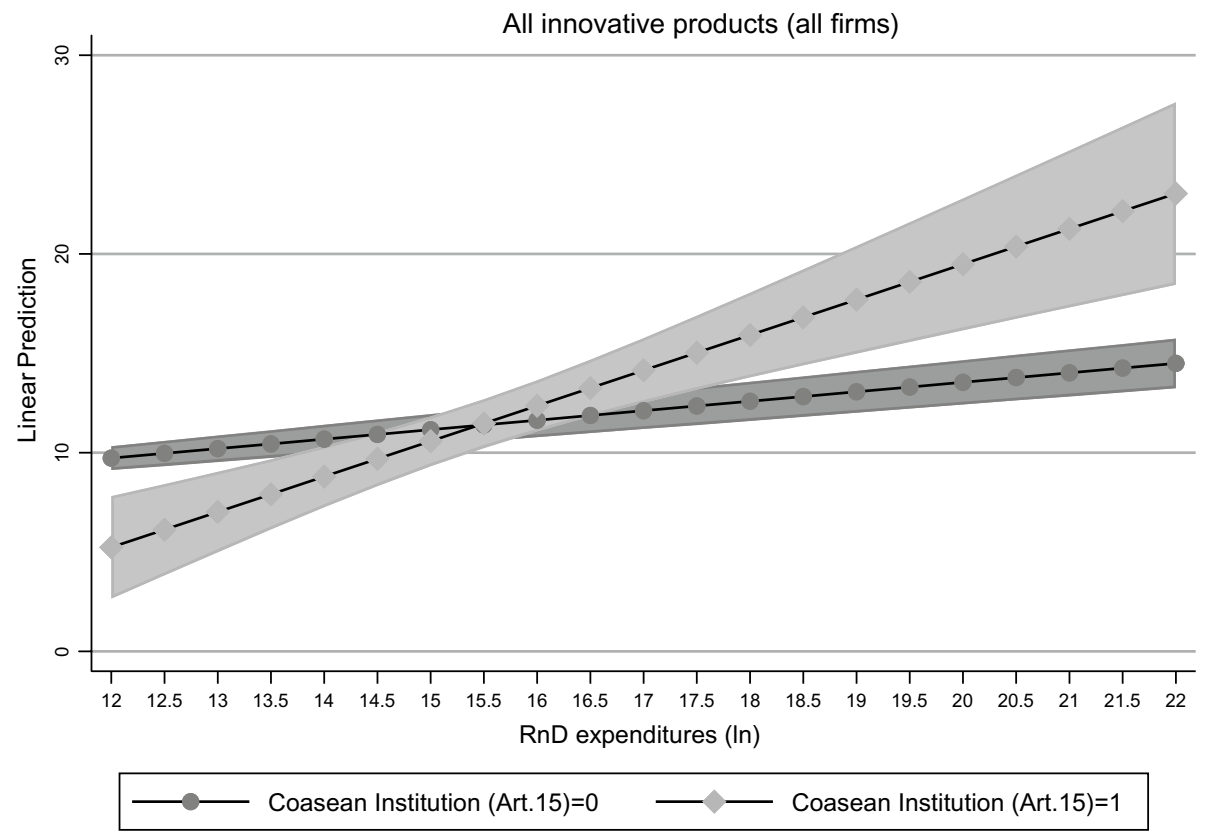

Fig. 1 Moderating effects of Coasean Institutions (all innovative products, all firms)

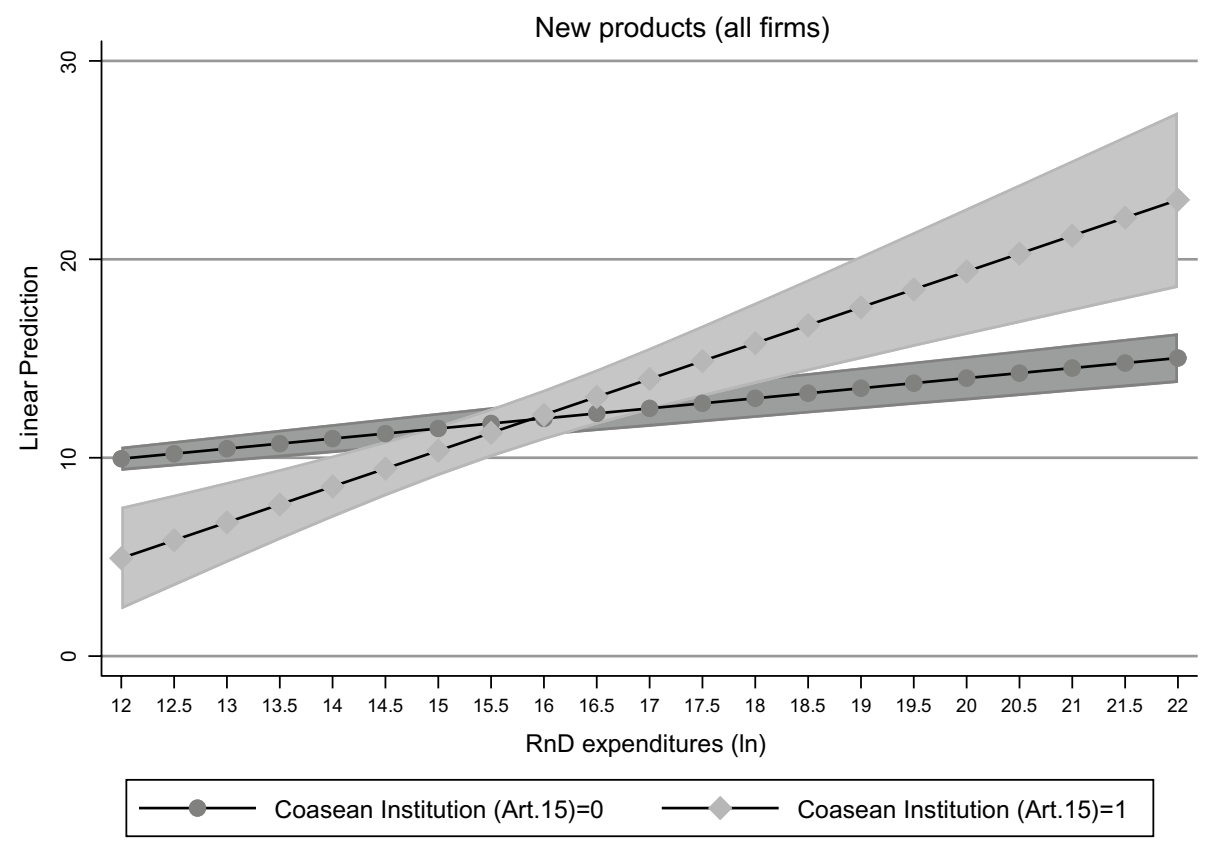

Fig. 2 Moderating effects of Coasean Institutions (New products, all firms) 


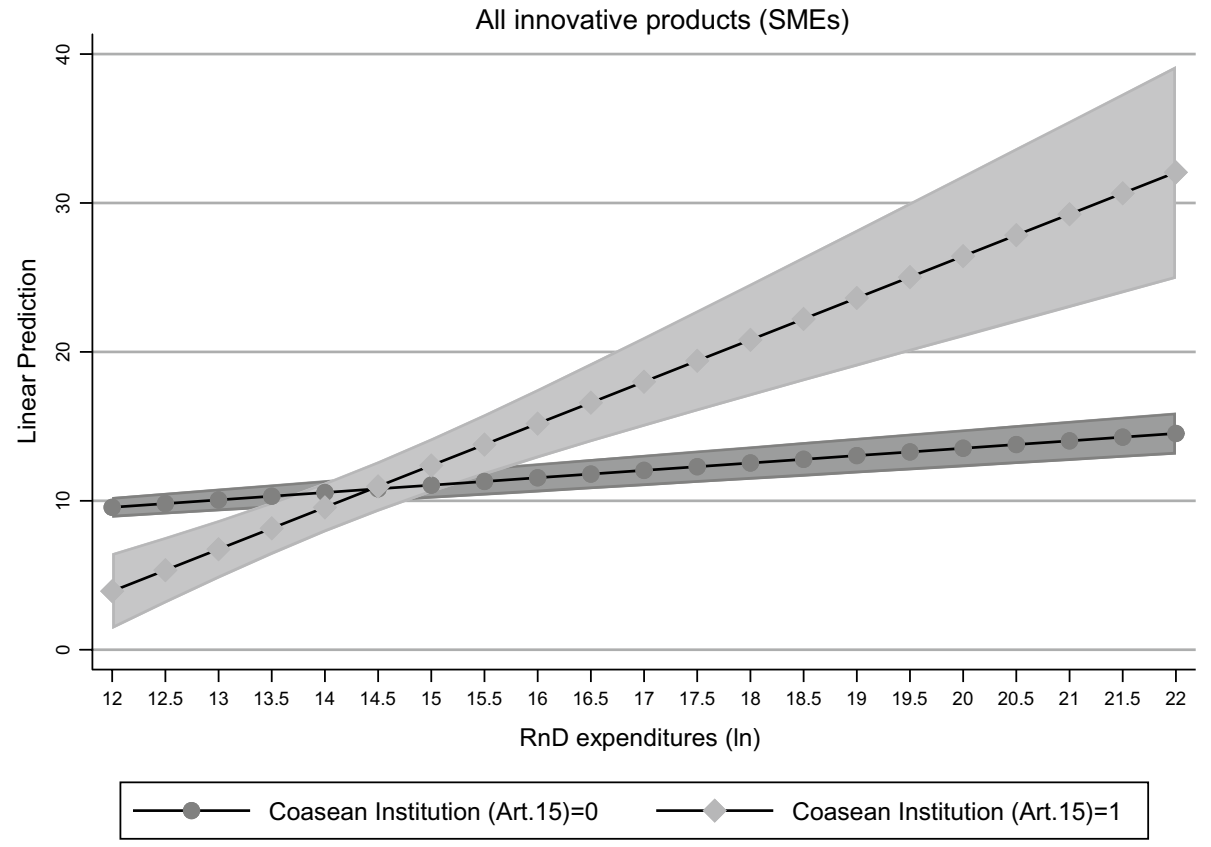

Fig. 3 Moderating effects of Coasean Institutions (all innovative products, SMEs)

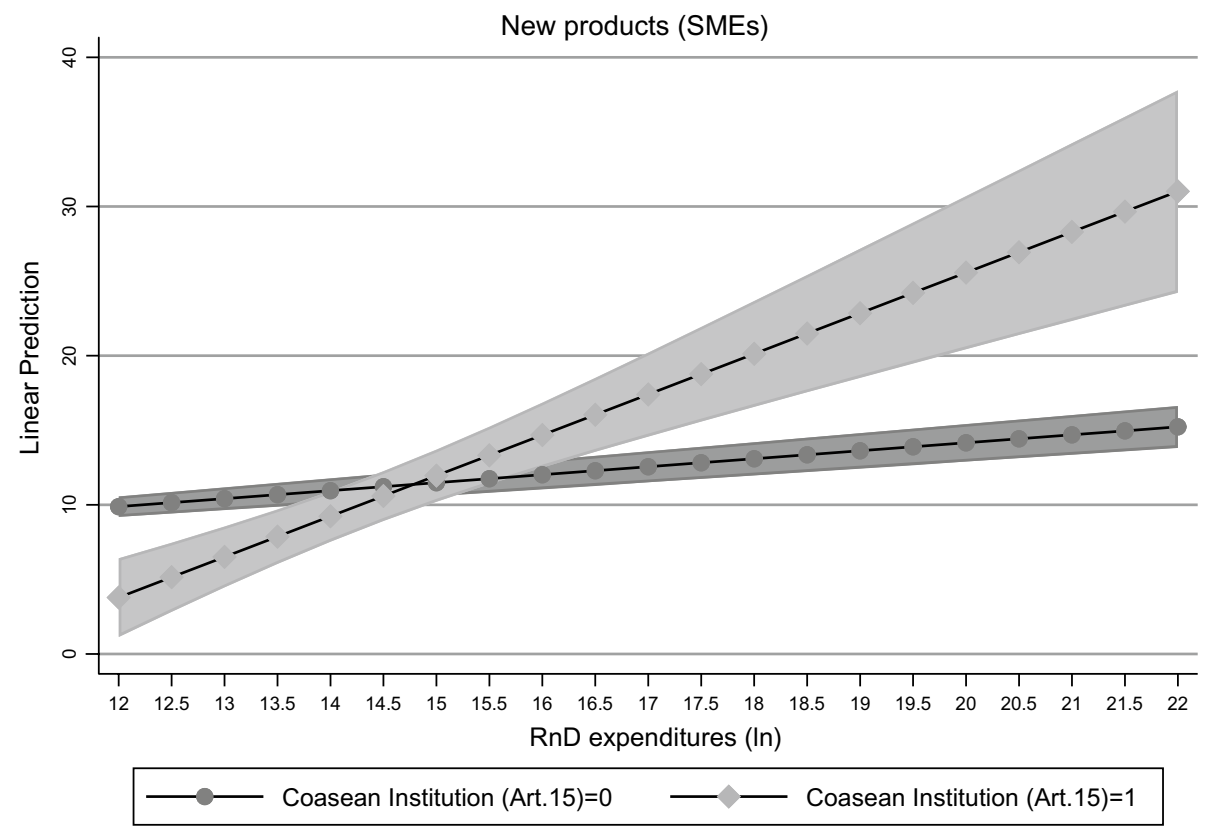

Fig. 4 Moderating effects of Coasean Institutions (New products, SMEs) 
firms with more than 5 employees. Stratification refers to 29 industries and, within the single industries, to three firm size classes. These surveys do not provide information about collaborations with Inspire, however we could use the information on R\&D collaboration to develop an auxiliary construction for measuring Coasean institutions. The robustness tests with the alternative data set largely confirm the main findings.

We measured the innovation performance by the sales of new products and the sales of essentially modified products, respectively. Hence, we could investigate the meaning of such an institutional setting for more advanced and less advanced innovative products taking into account the absorptive capacity of a company. In econometric terms, we investigated the moderating effects of Coasean institutions for the innovation performance of companies.

Our most important econometric findings are: (1) Coasean institutions are positively related with both, the sales of new products and the sale of essentially modified products only if the company has a sufficiently large absorptive capacity for external knowledge. (2) This positive moderating effect of Coasean institutions for the innovation performance is significantly larger for SMEs. (3) We measure the absorptive capacity of a company through its $R \& D$ investments. To achieve positive performance effects, these investments must be substantial, i.e. R\&D must be a core activity of the company. (4) We have conducted a number of robustness tests that does not only confirm the main results, but also show that competition and strong institutional ties are important for the performance effects.

Deriving policy implications from our empirical work is of course a delicate matter. The reason has already been suggested in the introduction. By definition, Coasean institutions weaken the main policy rationale-which is used in the domain of innovation and deals with knowledge spillovers as a market failure. Indeed, such institutions correct the potential market failure inherent in the private provision of specific public goods. However, the fact that we found that Coasean institutions have a significant positive effect on innovation performance only if the concerned companies have a sufficient large absorptive capacity, is a motivation to call for policies aimed at strengthening $R \& D$ activities in companies and increase the capacities of SMEs to create private institutions of this type. For example, there is a strong case for creating public programs that support the initial transaction costs of forming a club or that offer small subsidies to support some of the organization's operational costs after it has been established. These two options were used in the case of Inspire-which is classified as a Centre of Technological Excellence under Art. 15 of the Federal Act on the Promotion of Research and Innovation (RIPA) - , making it eligible for such subsidies.

Coasean institutions are particularly successful if there is a research-oriented SME landscape. It is therefore necessary to complement the measures to support these institutions with measures to promote the absorptive capacity of SMEs if it declines. Bloom et al. (2019) summarized the literature on policies to promote innovation and identified tax credits as a particularly effective instruments to increase the volume of R\&D.

Another important impulse can come from the organization of a "generous" ecosystem surrounding these types of institutions-which would make it possible to publicly fund some of the projects being developed. In the case of Inspire, we mentioned that, in many instances, project partners (research group and SMEs involved) apply for CTI funds, which, in the case of a successful application, are allocated to the research group (not to the SMEs). The availability of such grants and the fact that they are relatively abundant helps Inspire. The SMEs address issues such as financing and management 
of those R\&D projects that are long term, risky and complex and require substantial project-specific unrecoverable investments.

Finally, recognition of the fact that such institutions strongly enhance the innovation capacities of the SMEs involved also means that policies must support low-cost dissemination of the "lessons" learned from these institutions, as a means to encourage other firms to commit in such a process of collective action.

In his 1993 paper, Romer defined innovation policy as a process of creation and selection of institutions-effective institutions that can channel the energies of a large number of people towards research and innovation as well as effective institutions that can help private agents to exploit opportunities for collective actions. Encouraging the formation of Coasean institutions of the type described in this paper can certainly be considered as a "good" innovation policy à la Romer.

The focus of the paper at hand are the benefits for SMEs. However, the motivation of universities to participate in such partnerships have not been investigated in the statistical part of the paper; we only point at them in the case study. Given the lack of data, this type of investigation must be left for future research. Potential benefits for universities might be measured by publications, number of start-ups, number of recruited scientists/phDs, copatenting, and funding. Moreover, it would be interesting to see if the same setting would lead to similar results for other countries, with a different institutional history and innovation policy.

Funding Open access funding provided by Swiss Federal Institute of Technology Zurich.

Open Access This article is licensed under a Creative Commons Attribution 4.0 International License, which permits use, sharing, adaptation, distribution and reproduction in any medium or format, as long as you give appropriate credit to the original author(s) and the source, provide a link to the Creative Commons licence, and indicate if changes were made. The images or other third party material in this article are included in the article's Creative Commons licence, unless indicated otherwise in a credit line to the material. If material is not included in the article's Creative Commons licence and your intended use is not permitted by statutory regulation or exceeds the permitted use, you will need to obtain permission directly from the copyright holder. To view a copy of this licence, visit http://creativecommons.org/licenses/by/4.0/.

\section{References}

Aghion, P., David, P. A., \& Foray, D. (2009). Science, technology and innovation for economic growth: linking policy research and practice in 'STIG systems'. Research Policy, 38(4), 681.

Agrawal, A. (2001). University-to-industry knowledge transfer: Literature review and unanswered questions. International Journal of Management Reviews, 3(4), 285-302.

Antonelli, C., \& Patrucco, P. (2016). Organizational innovations, ICTs and knowledge governance: the case of platforms. In Johannes M. Bauer \& Michael Latzer (Eds.), Handbook on the Economics of the Internet, chapter 15 (pp. 323-343). Cheltenham: Edward Elgar Publishing.

Antonelli, C., \& Foray, D. (1992). The economics of technological clubs. Economics of Innovation and New Technology, 2(1), 37-47.

Arvanitis S., F.Seliger, A.Spescha, T. Stucki, \& Woerter, M. (2016). Die Entwicklung der Innovationsaktivitäten in der Schweizer Wirtschaft 1997-2014, Strukturberichterstattung Nr. 55, Staatssekretariat für Wirtschaft SECO, Bern, Schweiz.

Arvanitis, S., Ley, M., \& Woerter, M. (2012). Knowledge and Technology Transfer between Universities and Private Enterprises in Switzerland 2011 - an analysis based on firm and institute data. KOF-Studies, No. 37, KOF ETH Zürich, Zürich.

Arvanitis, S., \& Woerter, M. (2009). Firms' transfer strategies with universities and the relationship with firms' innovation performance. Industrial and Corporate Change, 18(6), 1067-1106. 
Arvanitis, S., Sydow, N., \& Woerter, M. (2008). Is there any impact of University-industry knowledge transfer on innovation and productivity? An Empirical Analysis Based on Swiss Firm Data, Review of Industrial Organization, 32(2), 77-94.

Beck, M., Hulfeld, F., Spescha, A., \& Woerter, M. (2019). Analysis of knowledge and technology transfer in Switzerland-The perspective of the enterprises. Zurich: KOF Study No.

Berger, S. (2013). Making in America. Cambridge (MA): The MIT Press.

Bloom, N., Van Reenen, J., \& Williams, H. (2019). A toolkit of policies to promote innovation. Journal of Economic Perspectives, 33(3), 163-184. https://doi.org/10.1257/jep.33.3.163.

Bozeman, B. (2000). Technology transfer and public policy: A review of research and theory. Research Policy, 29, 627-655.

Branstetter, L., \& Sakakibara, M. (2002). When do research consortia work well and why? Evidence from Japanese panel data. American Economic Review, 92(1), 143-159.

Breiding, J., \& Schwarz, G. (2011). WirtschafswunderSchweiz. Zürich: Verlag NZZ.

Browning, L., Beyer, J., \& Shetler, J. (1995). Building cooperation in a competitive industry: SEMATECH and the semiconductor industry. The Academy of Management Journal, 38(1), 113-151.

Callaert, J., van Looy, B., Foray, D., \& Debackere, K. (2008). Combining the production and the valorization of academic research: A qualitative investigation of enacted mechanisms. In C. Mazza, P. Quattrone, \& A. Riccaboli (Eds.), European Universities in transition. Cheltenham: Edward Elgar.

Cassier, M., \& Foray, D. (2002). Public knowledge, private property and the economics of high-tech consortia. Economics of Innovation and New Technology, 11(2), 123-132.

Cassiman, B., \& Veugelers, R. (2002). R\&D Cooperation and Spillovers: Some empirical evidence from Belgium. American Economic Review, 92(4), 1169-1184.

Coase, R. (1937). The nature of the firm. Economica, 4, 386-405.

Coase, R. (1960). The problem of social costs. Journal of Law and Economics, 3, 1-44.

Cockburn I., Henderson R. \& Stern S. (1999). The diffusion of science-driven drug discovery: Organizational change in pharmaceutical research, NBER working paper, no. 7559, Cambridge MA.

Cohen, W. (2010). Fifty years of empirical studies of innovative activity and performance. In B. Hall \& N. Rosenberg (Eds.), Economics of Innovation, Handbooks in Economics. Amsterdam: North-Holland.

Cohen, W., \& Levinthal, D. (1989). Innovation and learning: The two faces of R\&D. Economic Journal, 99(397), 569-596.

Cohen, W., \& Levinthal, D. (1990). Absorptive capacity: A new perspective on learning and innovation. Administrative Science Quarterly, 35(1), 128-152.

David P.A. \& Metcalfe S. (2008). "Only connect": academic-business research collaborations and the formation of ecologies of innovation, SIEPR working paper 07-33, Stanford Institute for Economic Policy Research.

Foray, D., \& Hollanders, H. (2015). An assessment of the Innovation Union Scoreboard as a tool to analyse national innovation capacities: The case of Switzerland. Research Evaluation, 24(2), 213-228.

Foray, D., \& Lissoni, F. (2010). University research and public-private interactions. In B. H. Hall \& N. Rosenberg (Eds.), Economics of innovation handbooks in economics. Amsterdam: North Holland.

Ghemawat, P. (2017). Market and Management Failures. Capitalism and Society, 12(1), 27.

Grindley, P., Mowery, D., \& Silverman, B. (1994). SEMATECH and collaborative research: Lessons in the design of high technology consortia. Journal of Policy Analysis and Management, 13, 723-785.

Hausmann, R., \& Rodrik, D. (2006). Doomed to Choose: Industrial Policy as Predicament. Cambridge: Center for International Development, Harvard University.

Kelley, M., \& Arora, A. (1996). The role of institution-building in US industrial modernization programs. Research Policy, 25(2), 265-280.

Powell, W., \& Giannella, E. (2010). Collective invention and innovator networks. In B. H. Hall \& N. Rosenberg (Eds.), Economics of Innovation Handbooks in Economics. Amsterdam: North Holland.

Rodrik, D. (2007). Industrial Policy for the Twenty-first Century. Discussion Paper Series $\mathrm{n}^{\circ} 4767$. London: Center for Economic Policy Research.

Romer, Paul M., \& Griliches, Z. (1993). Implementing a national technology strategy with self-organizing industry investment boards. Brookings Papers on Economic Activity Microeconomics, 2, 345-399.

Sabel, C. (1996). A measure of federalism: assessing manufacturing technology centers. Research Policy, 25(2), 281-308.

SBFI. (2016). Research and Innovation in Switzerland. Bern: Swiss Confederation.

Schlich, T. (2002). Surgery, science and industry—a revolution in fracture care-1950s-1990s. London: Palgrave Macmillan.

Siegel, D. S., Thursby, J. G., Thursby, M. C., \& Ziedonis, A. (2001). Organizational issues in universityindustry technology transfer: An overview of the symposium issue. Journal of Technology Transfer, $26(1 \& 2), 5-11$. 
Thursby, J. G., \& Thursby, M. C. (2003). Industry/university licensing: characteristics, concerns and issues from the perspective of the buyer. The Journal of Technology Transfer, 28, 207-213.

Weder, R., \& Grubel, H. (1993). The new growth theory and Coasean economics: Institutions to capture externalities. WeltwirschaftlichesArchiv, 129(3), 488-513.

Ynnon, E. (1996). The shift to knowledge-intensive product in the plastis-processing industry and its implications for infrastructure development: Three case studies. Research Policy, 25(1), 163-179.

Zucker, L., \& Darby, M. (1998). The economist's case of biomedical research. In S. Barfield (Ed.), The Future of Biomedical Research. Washington D.C: AEI Press.

Zucker, L. G., \& Darby, M. R. (1996). Start scientists and institutional transformation: Patterns of invention and innovation in the formation of biotechnology industry. In Proceedings of the National Academy of Sciences of the United States of America (pp. 12709-12716). Colloquium Paper 93.

Publisher's Note Springer Nature remains neutral with regard to jurisdictional claims in published maps and institutional affiliations. 